\title{
A!
}

This is an electronic reprint of the original article.

This reprint may differ from the original in pagination and typographic detail.

Jin, Hua; Hagen, Dirk; Karppinen, Maarit

\section{Low-temperature atomic layer deposition of crystalline manganese oxide thin films}

Published in:

Dalton Transactions

DOI:

10.1039/c6dt03040h

Published: 01/01/2016

Document Version

Peer reviewed version

Published under the following license:

Unspecified

Please cite the original version:

Jin, H., Hagen, D., \& Karppinen, M. (2016). Low-temperature atomic layer deposition of crystalline manganese oxide thin films. Dalton Transactions, 45(46), 18737-18741. https://doi.org/10.1039/c6dt03040h

This material is protected by copyright and other intellectual property rights, and duplication or sale of all or part of any of the repository collections is not permitted, except that material may be duplicated by you for your research use or educational purposes in electronic or print form. You must obtain permission for any other use. Electronic or print copies may not be offered, whether for sale or otherwise to anyone who is not an authorised user. 


\section{Dalton Transactions}

\section{ARTICLE}

\section{Low-temperature atomic layer deposition of crystalline manganese oxide thin films}

Received 00th January 20xx Accepted 00th January 20xx

DOI: $10.1039 / x 0 x \times 00000 x$

www.rsc.org/

\begin{abstract}
Hua Jin ${ }^{a}$, Dirk Hagen ${ }^{a}$ and M aarit Karppinen ${ }^{2 *}$
We present a new low-temperature atomic layer deposition (ALD) process based on $\mathrm{Mn}_{2}(\mathrm{CO})_{10}$ and ozone as precursors to fabricate crystalline $\alpha-\mathrm{M} \mathrm{n}_{2} \mathrm{O}_{3}$ and $\mathrm{Mn}_{3} \mathrm{O}_{4}$ thin films; the phase composition is controlled by the deposition temperature such that the former phase forms in the range $60 \sim 100{ }^{\circ} \mathrm{C}$ and the latter in the range $120 \sim 160{ }^{\circ} \mathrm{C}$. In both cases an appreciably high growth rate of $\sim 1.2 \AA /$ cycle is achieved. The spinel-structured $\mathrm{M} \mathrm{n}_{3} \mathrm{O}_{4}$ thin films are shown to be ferrimagnetic with the transition temperature determined at $\sim 7 \mathrm{~K}$.
\end{abstract}

\section{Introduction}

Manganese oxides form an interesting family of functional materials with a variety of attractive properties. These materials are already found in several important applications, and actively considered for a number of potential next-generation applications related to e.g. catalysis, batteries and supercapacitors. ${ }^{1-5}$ Moreover, manganese is more abundant and environmentally friendlier than most of the other transition metals. Manganese forms oxides such as $\mathrm{MnO}, \mathrm{Mn}_{3} \mathrm{O}_{4}, \mathrm{Mn}_{2} \mathrm{O}_{3}$ and $\mathrm{MnO}_{2}$ with different oxidation states and with a number of polymorphs. For example, the tetravalent manganese oxide $\mathrm{MnO}_{2}$ performs differently in electrochemical and catalytic applications depending on its crystal structure, i.e. whether it exists in the form of $\alpha, \beta, \gamma, \delta, \varepsilon$ or $\lambda$ phase..$^{1-5}$ One of the practical challenges is to fabricate the manganese oxide materials with the desired $\mathrm{Mn}$ oxidation state and the specific crystal structure, and also to engineer these materials into different application-required nanostructures. In particular, there is an increasing demand for high-quality thin films due to the development of microsystems. Electrodeposition, electrophoresis, dip coating, sol-gel methods, chemical vapour deposition (CVD), and atomic layer deposition (ALD) have been utilized for the deposition of manganese oxide thin films. ${ }^{2-16}$

Among the different thin-film deposition techniques, ALD with its unique film growth mechanism based on self-limiting surface reactions between alternately introduced gaseous precursors is superior to the other techniques regarding the film uniformity and conformity. ${ }^{3-16}$ In spite of the increasing demand for techniques capable of producing high-quality manganese oxide thin films on various substrate architectures and the fast development of the ALD technology in general, only a few ALD processes for the growth of manganese oxides have been reported thus far. ${ }^{6-23}$ In these processes, only two different manganese precursors have been utilized, namely $\mathrm{Mn}(\text { thd })_{3}$ (thd $=2,2,6,6$-tetramethylheptane-3,5-dionate) with $\mathrm{O}_{3}$ as the oxygen source and $\mathrm{Mn}(\mathrm{CpEt})_{2}(\mathrm{CpEt}=$ ethylcyclopentadienyl) combined with $\mathrm{H}_{2} \mathrm{O}$. The former $\mathrm{Mn}(\text { thd })_{3}+\mathrm{O}_{3}$ process yields crystalline $\mathrm{MnO}_{2}$ films, with the growth-per-cycle (GPC) values of $\sim 0.2 \AA /$ cycle within the deposition temperature window from 138 to $210{ }^{\circ} \mathrm{C} .6-8$ With the latter $\mathrm{Mn}(\mathrm{CpEt})_{2}+\mathrm{H}_{2} \mathrm{O}$ process, $\mathrm{MnO}$ films with considerably higher GPC values of $\sim 1.1 \AA /$ cycle at $100-150{ }^{\circ} \mathrm{C}$ and $0.84 \AA /$ cycle at $170{ }^{\circ} \mathrm{C}$ have been grown. 8,13 Besides these conventional thermal ALD processes, three plasma-enhanced PE-ALD processes with ammonia, hydrogen and water plasma were recently developed based on the $\mathrm{Mn}$ (thd) ${ }_{3}$ precursor; ${ }^{18}$ most importantly, the different activated reactant gases utilized in these processes allowed the control of the oxidation state of manganese in the films. The GPC values reached were somewhat low though, e.g. $\sim 0.2 \AA /$ cycle with the ammonia plasma in the temperature window of 150 to $255^{\circ} \mathrm{C}$.

In this work, we employ for the first time a new zero-valent manganese precursor, manganese carbonyl $\mathrm{Mn}_{2}(\mathrm{CO})_{10},{ }^{21,22}$ for the low-temperature deposition of crystalline $\mathrm{Mn}_{2} \mathrm{O}_{3}$ and $\mathrm{Mn}_{3} \mathrm{O}_{4}$ thin films with the appreciably high growth rates of up to $\sim 1.5 \AA /$ cycle. Moreover, we demonstrate the successful control of the phase composition from $\mathrm{Mn}_{2} \mathrm{O}_{3}$ to $\mathrm{Mn}_{3} \mathrm{O}_{4}$ of the films by adjusting the deposition temperature. For the spinelstructured $\mathrm{Mn}_{3} \mathrm{O}_{4}$ films we also report the results of preliminary magnetic-property measurements.

\footnotetext{
a. Laboratory of Inorganic Chemistry, Department of Chemistry, Aalto University,

P.O. Box 16100, FI-00076 AALTO, Espoo, Finland.

*E-mail: maarit.karppinen@aalto.fi; Fax: +358 9462 73; Tel: +358 503841726
} 


\section{Results and discussion}

Our $\mathrm{M} \mathrm{n}_{2}(\mathrm{CO})_{10}+\mathrm{O}_{3}$ process yielded visually homogeneous thin films within the entire deposition temperature range of 60-200 ${ }^{\circ} \mathrm{C}$ studied. With deposition temperatures higher than $200{ }^{\circ} \mathrm{C}$, the reaction turned out to be of the CVD type, and the films were notably rough. The controlled/constant deposition rate is arguably the most important feature of an ideal ALD process. Hence, saturation of the surface reactions was the first issue investigated here as well. In Fig. 1 we show the variation of the GPC value with varied precursor pulse lengths for our manganese oxide thin films deposited from $\mathrm{Mn}_{2}(\mathrm{CO})_{10}$ and $\mathrm{O}_{3}$ at $80{ }^{\circ} \mathrm{C}$. At this relatively low deposition temperature the maximal GPC value of $\sim 1.2 \AA /$ cycle is obtained with a $M n_{2}(C O)_{10}$ pulse length of $2 \mathrm{~s}$; for the longer pulse lengths the GPC value remains the same, and even for the $\mathrm{Mn}_{2}(\mathrm{CO})_{10}$ pulse length as short as $1 \mathrm{~s}$ the resultant GPC value is only slightly lower. Also for the $\mathrm{O}_{3}$ pulse, the pulse length of $2 \mathrm{~s}$ was found sufficient to achieve the saturation, see Fig. 1 . In these depositions the $\mathrm{N}_{2}$ purging length for both the reactants was fixed at $6 \mathrm{~s}$ based on our preliminary experiments. For the rest of the deposition experiments we employed the following ALD cycle: $2 \mathrm{~s}$ $\mathrm{Mn}_{2}(\mathrm{CO})_{10} / 6 \mathrm{~s} \mathrm{~N}_{2} / 2 \mathrm{sO}_{3} / 6 \mathrm{sN}_{2}$.
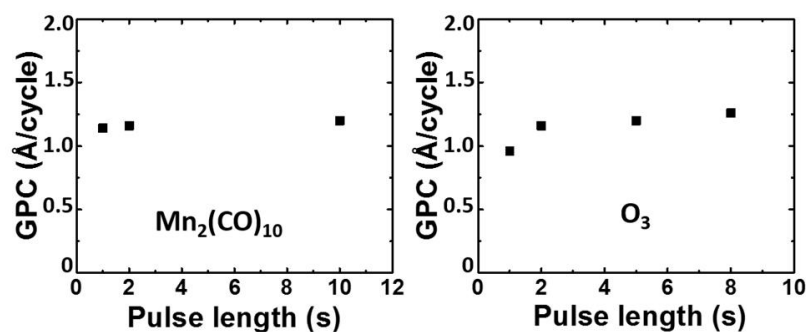

Fig. 1 Dependence of the GPC value on the precursor pulse lengths, $\mathrm{Mn}_{2}(\mathrm{CO})_{10}$ (left) and $\mathrm{O}_{3}$ (right), at the deposition temperature of $80^{\circ} \mathrm{C}$.

Next we investigated the effect of the deposition temperature, varied from 60 to $160{ }^{\circ} \mathrm{C}$, in order to confirm the temperature window for the depositions within which the depositions are well controlled and reproducible. The starting point of $60{ }^{\circ} \mathrm{C}$ for our temperature-search experiments was defined by the $\mathrm{M}_{2}(\mathrm{CO})_{10}$ sublimation temperature of $55^{\circ} \mathrm{C}$, as the deposition temperature cannot be lower than the temperatures of the precursor sources. As can be seen in Fig. 2, the growth rate is $-0.60 \AA /$ cycle at $60^{\circ} \mathrm{C}$, and it increases to $\sim 1.2$ $\AA$ /cycle when the deposition temperature is $80^{\circ} \mathrm{C}$ or higher. The GPC value remains essentially constant up to $120^{\circ} \mathrm{C}$, then increases further being $\sim 1.35 \AA /$ cycle at $140^{\circ} \mathrm{C}$ and $\sim 1.5 \AA /$ cycle at $160^{\circ} \mathrm{C}$. We also tested depositions at $200^{\circ} \mathrm{C}$, and for these depositions, the observed GPC value somewhat varied from experiment to experiment. The increase of the growth rate at the higher deposition temperatures could be attributed to the partial decomposition of the manganese precursor. We like to emphasize that the depositions were well-controlled and reproducible at least in the deposition temperature range of $80-160^{\circ} \mathrm{C}$. The general criteria of an ideal ALD-type film growth, i.e. the so-called growth linearity, was tested at $80{ }^{\circ} \mathrm{C}$ as is shown in Fig. 2 by varying the number of ALD cycles between 300 and 800: with increasing number of deposition cycles the film thickness increases in an essentially linear manner with no visible nucleation delay in the beginning. Furthermore, when the substrate was exposed to $\mathrm{Mn}_{2}(\mathrm{CO})_{10}$ without an oxygen source at $200{ }^{\circ} \mathrm{C}$ (400 cycles, 4s pulse length), no $\mathrm{Mn}$ was detectable with X-ray fluorescence (XRF) confirming that no CVD type growth by pyrolysis of the precursor occurs within the ALD window.
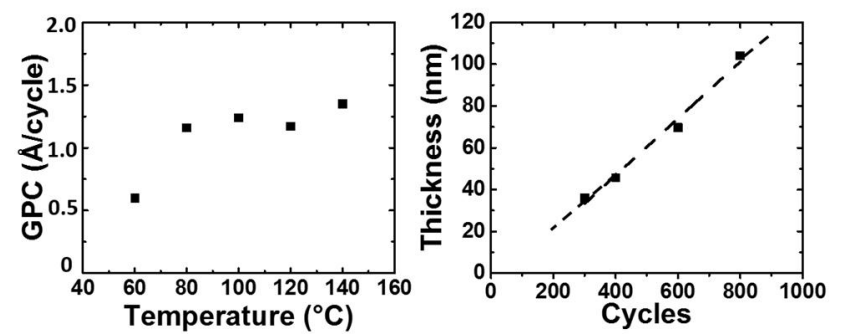

Fig. 2 (Left) Dependence of the GPC value on the deposition temperature. (Right) Film thickness versus number of ALD cycles for films deposited at $80^{\circ} \mathrm{C}$; the dash line is fitted to the data points, $R^{2}=0.987$.

In Fig. 3, we display GIXRD patterns recorded for our manganese oxide thin films deposited at different temperatures from 80 up to $200{ }^{\circ} \mathrm{C}$. All the films are crystalline. At temperatures between $80-100{ }^{\circ} \mathrm{C}$, our $\mathrm{Mn}_{2}(\mathrm{CO})_{10}+\mathrm{O}_{3}$ process results in films of the cubic $\alpha-\mathrm{Mn}_{2} \mathrm{O}_{3}$ phase. When increasing the deposition temperature to $120{ }^{\circ} \mathrm{C}$ or higher the product is $\mathrm{Mn}_{3} \mathrm{O}_{4}$ of the tetragonally-distorted spinel structure. For both the phases, increasing the deposition temperature within the respected temperature windows leads to the higher degree of crystallinity. In the case of the $\mathrm{M} \mathrm{n}_{3} \mathrm{O}_{4}$ phase, the film deposited at $120^{\circ} \mathrm{C}$ shows a sharp peak at $18.0^{\circ}$ corresponding to the 101 reflection and weaker peaks at the $2 \theta$ angles of 32.4, 36.1, 60.0 and $65.5^{\circ}$ assigned to the 103, 211, 224 and 323 reflections, respectively. Then, with increasing deposition temperature new peaks corresponding to the 004, 220 and 321 reflections appear, indicating the enhanced crystallinity of the films. For the $\alpha-\mathrm{Mn}_{2} \mathrm{O}_{3}$ phase, the GIXRD pattern of the film deposited at $100{ }^{\circ} \mathrm{C}$ shows clear peaks at $23.1,33.0,40.7$ and $55.2^{\circ}$ due to the $211,222,411$ and 440 reflections. 


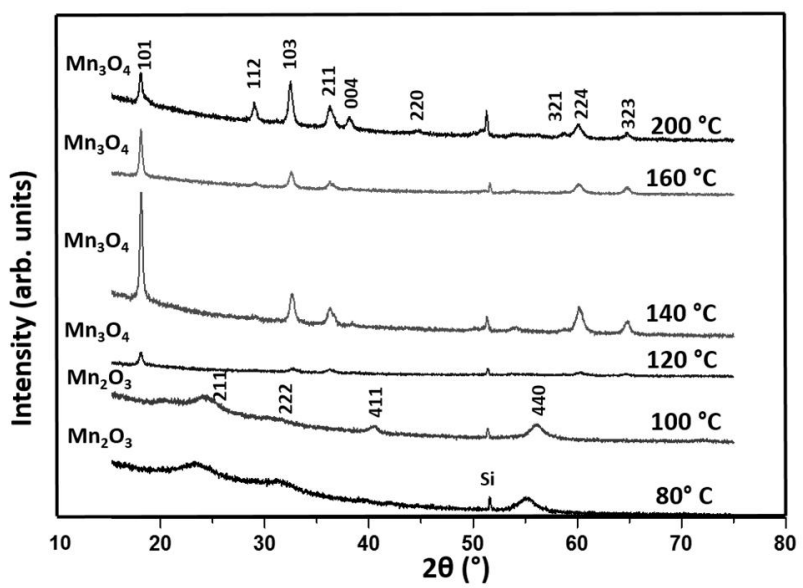

Fig. 3 GIXRD patterns for our manganese oxide thin films deposited at different temperatures.

Since the GIXRD peaks for our low-temperature deposited $\mathrm{Mn}_{2} \mathrm{O}_{3}$ thin films are relatively broad we sought additional evidence for the trivalent state of manganese in these films from XPS measurements. The M n 2p and 3s XPS spectra shown in Fig. 4 for the two samples deposited at 80 and $100{ }^{\circ} \mathrm{C}$ are fully consistent with trivalent $\mathrm{Mn}$ (within the accuracy of the measurement): there is no satellite feature seen between the $M n 2 p_{1 / 2}$ and $M n 2 p_{3 / 4}$ peaks in the $2 p$ spectra around $647 \mathrm{eV}$ due to divalent $M n$, and in the $M n$ 3s spectra the splitting of the two multiplet-split components (ca. $5.5 \mathrm{eV}$ ) is what one could expect for the trivalent $\mathrm{Mn}$ state. $24,25 \mathrm{M}$ oreover seen from Fig. 4 is that the spectra for the two samples deposited at 80 and $100{ }^{\circ} \mathrm{C}$ are essentially equivalent.
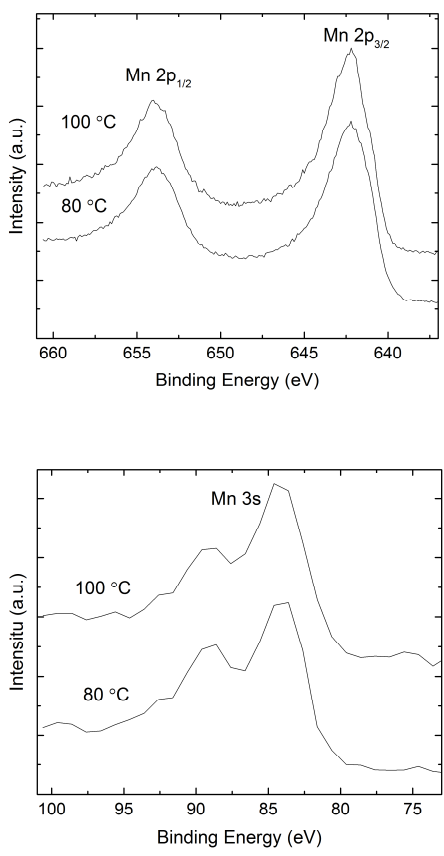

Fig. $4 \mathrm{Mn} 2 \mathrm{p}$ and $3 s$ XPS spectra for two thin-film samples deposited at 80 and $100{ }^{\circ} \mathrm{C}$.
In Table 1, we compare the phase compositions and growth rates realized for our $\mathrm{Mn}_{2}(\mathrm{CO})_{10}+\mathrm{O}_{3}$ process at different deposition temperatures to those reported in previous literature for the two thermal ALD processes, $\mathrm{Mn}(\text { thd })_{3}+\mathrm{O}_{3}$ for $\mathrm{MnO}_{2}$ and $\mathrm{Mn}(\mathrm{CpEt})_{2}+\mathrm{H}_{2} \mathrm{O}$ for $\mathrm{MnO}$, and the recently developed PE-ALD processes with ammonia, hydrogen and water plasma. For the thermal $\mathrm{Mn}$ (thd $)_{3}+\mathrm{O}_{3}$ process for $\mathrm{MnO}_{2}$, the $\mathrm{GPC}$ values achieved are distinctly low $(\sim 0.2 \AA /$ cycle $){ }^{6-8}$ With the $\mathrm{Mn}(\mathrm{CpEt})_{2}+\mathrm{H}_{2} \mathrm{O}$ process, $\mathrm{MnO}$ films have been deposited with the higher rates up to $1.2 \AA$ / cycle. ${ }^{9}$ For the plasma processes the GPC values achieved are low $(\sim 0.2 \AA /$ cycle $),{ }^{18}$ but the advantage is the possibility to control the oxidation state of manganese by the redox nature of the reactant gases. From Table 1, the GPC values of our $\mathrm{Mn}_{2}(\mathrm{CO})_{10}+\mathrm{O}_{3}$ process are indeed appreciably high. Moreover, the lowest deposition temperatures of 60-80 ${ }^{\circ} \mathrm{C}$ are essentially lower than those feasible for the previously reported processes. The low deposition temperatures are of particular benefit for potential applications based on temperature-sensitive substrates such as polymers and textiles. ${ }^{26}$ M ost importantly, the low deposition temperatures turned out to be the key for us to be able to deposit the thin films of the metastable $\mathrm{Mn}_{2} \mathrm{O}_{3}$ phase for the first time by ALD.

We also investigated the effects of post-deposition heat treatments. In particular we wanted to see the phase stability of the $\mathrm{Mn}_{2} \mathrm{O}_{3}$ phase at elevated temperatures. We thus annealed our $\mathrm{Mn}_{2} \mathrm{O}_{3}$ films deposited at $100{ }^{\circ} \mathrm{C}$ in an oven in air at 400,500 and $600{ }^{\circ} \mathrm{C}$. As seen from the resultant GIXRD patterns (not shown here) the crystalline phase in the films changed from $\mathrm{M} \mathrm{n}_{2} \mathrm{O}_{3}$ to $\mathrm{M} \mathrm{n}_{3} \mathrm{O}_{4}$ upon the annealing, even at the lowest annealing temperature of $400{ }^{\circ} \mathrm{C}$. With increasing annealing temperature, the diffraction peaks due to the $\mathrm{M} \mathrm{n}_{3} \mathrm{O}_{4}$ phase got sharper, as expected. Hence post-deposition heat treatments may be considered in case the degree of crystallinity of $\mathrm{Mn}_{3} \mathrm{O}_{4}$ thin films should be further enhanced.

Table 1 Summary of the products and growth rates for different ALD processes for manganese oxide thin films regarding the deposition temperature, from literature and the present work.

\begin{tabular}{|c|c|c|c|c|}
\hline Dep. temp. $\left({ }^{\circ} \mathrm{C}\right)$ & Product & Precursors and process & GPC ( $(\AA /$ cycle $)$ & Ref. \\
\hline 60 & $\mathrm{Mn}_{2} \mathrm{O}_{3}$ & $\mathrm{Mn}_{2}(\mathrm{CO})_{10}+\mathrm{O}_{3} ;$ Thermal & 0.60 & present \\
\hline 80 & $\mathrm{Mn}_{2} \mathrm{O}_{3}$ & $\mathrm{Mn}_{2}(\mathrm{CO})_{10}+\mathrm{O}_{3}$; Thermal & 1.16 & present \\
\hline 100 & $\mathrm{MnO}$ & $\mathrm{Mn}(\mathrm{EtCp})_{2}+\mathrm{H}_{2} \mathrm{O}$; Thermal & 1.2 & 9 \\
\hline 100 & $\mathrm{Mn}_{2} \mathrm{O}_{3}$ & $\mathrm{Mn}_{2}(\mathrm{CO})_{10}+\mathrm{O}_{3} ;$ Thermal & 1.24 & present \\
\hline 120 & $\mathrm{Mn}_{3} \mathrm{O}_{4}$ & $\mathrm{Mn}_{2}(\mathrm{CO})_{10}+\mathrm{O}_{3}$; Thermal & 1.17 & present \\
\hline 140 & $\mathrm{Mn}_{3} \mathrm{O}_{4}$ & $\mathrm{Mn}_{2}(\mathrm{CO})_{10}+\mathrm{O}_{3}$; Thermal & 1.35 & present \\
\hline 150 & $\mathrm{MnO}_{2}$ & $\mathrm{Mn}(\text { thd })_{3}+\mathrm{O}_{3 ;}$. Plasma & 0.15 & 18 \\
\hline 150 & $\mathrm{MnO}$ & $\mathrm{Mn}(\text { thd })_{3}+\mathrm{NH}_{3} ;$ Plasma & 0.22 & 18 \\
\hline 160 & $\mathrm{Mn}_{3} \mathrm{O}_{4}$ & $\mathrm{Mn}_{2}(\mathrm{CO})_{10}+\mathrm{O}_{3} ;$ Thermal & 1.52 & present \\
\hline 170 & $\mathrm{MnO}$ & $\mathrm{Mn}(\mathrm{EtCp})_{2}+\mathrm{H}_{2} \mathrm{O}$; Thermal & 0.84 & 19 \\
\hline 186 & $\mathrm{MnO}_{2}$ & $\mathrm{Mn}$ (thd $)_{3}+\mathrm{O}_{3}$; Thermal & 0.2 & 6 \\
\hline
\end{tabular}


Lastly we discuss the magnetic properties of our spinelstructured $\mathrm{Mn}_{3} \mathrm{O}_{4}$ thin films. It is well known that the various manganese oxides display a variety of magnetic properties: $\mathrm{MnO}$ is antiferromagnetic, $\mathrm{M} \mathrm{n}_{3} \mathrm{O}_{4}$ is ferrimagnetic with a Curie temperature between 39 and $43 \mathrm{~K}$ depending on its microstructure and $\alpha-\mathrm{Mn}_{2} \mathrm{O}_{3}$ is antiferromagnetic. ${ }^{27-29}$ Fig. 5 shows magnetic hysteresis loops and a magnetic moment versus temperature characteristic for our $35 \mathrm{~nm}$ thick $\mathrm{Mn}_{3} \mathrm{O}_{4}$ film deposited at $200{ }^{\circ} \mathrm{C}$ (the high deposition temperature was selected - though being outside of the ALD window - as it yielded most highly crystalline films). It is apparent that the material is ferrimagnetic as expected. The magnetization per formula unit was calculated using the sample dimensions ( $3.5 \mathrm{x}$ $14.0 \mathrm{~mm}^{2}$ ), the film thickness ( $35 \mathrm{~nm}$ ), and a density of 4.86 $\mathrm{g} / \mathrm{cm}^{2}$ assuming that no other phases than $\mathrm{Mn}_{3} \mathrm{O}_{4}$ is present. The obtained saturation magnetization value of $0.9 \mu \mathrm{B}$ is lower than most reported values which are typically between 1.4 and $1.85 \mu \mathrm{B}, 27,28,30,31$ although values as low as $0.7 \mu \mathrm{B}$ have been reported for nanostructures. ${ }^{29}$ The Curie temperature of $47 \mathrm{~K}$ was obtained from a zero-field temperature loop which is compatible with literature values.
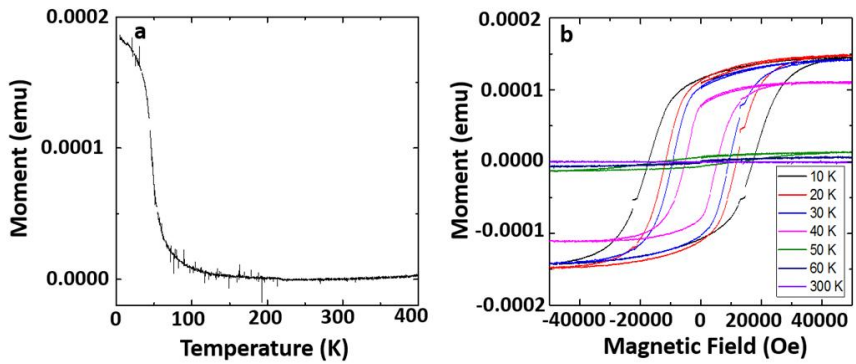

Fig. $5 \mathrm{M}$ agnetic properties of as deposited $\mathrm{Mn}_{3} \mathrm{O}_{4}$ thin film grown at $200{ }^{\circ} \mathrm{C}$ with thickness of $35 \mathrm{~nm}$ : (a) magnetization vs temperature at a field of $10000 \mathrm{Oe}$, (b) hysteresis sloops. The diamagnetic contribution was subtracted.

\section{Experimental}

Thin films of manganese oxides were deposited in an ASM F-120 reactor using Si wafers (p-type 100, Okmetic Ltd.) as substrates. Nitrogen was used as the carrier and purge gas in the depositions. During the deposition, the reactor was kept at a pressure of ca. 2-3 mbar (1.5-2 Torr). M anganese carbonyl was used as the precursor and $\mathrm{O}_{3}$ was used as the oxygen source in the depositions. The sublimation temperature for manganese carbonyl was $55^{\circ} \mathrm{C}$. Depositions were carried out from 60 to 160 ${ }^{\circ} \mathrm{C}$ to investigate the optimal temperature window. At a reaction temperature of $80^{\circ} \mathrm{C}$, the pulse lengths for manganese carbonyl and $\mathrm{O}_{3}$ were varied between 1 and $10 \mathrm{~s}$, and 1 and $8 \mathrm{~s}$, respectively.

The film thicknesses were measured with an X-ray reflectivity (XRR) instrument from PANalytical (X'Pert M PD PRO
Alfa 1). Grazing incident X-ray diffraction (GIXRD; X'Pert M PD PRO Alfa 1, PANalytical; Cu-Ka radiation) measurements were carried out to investigate the crystallinity of the samples. The valence of manganese in selected thin-film samples was investigated with $\mathrm{x}$-ray photoelectron spectroscopy (XPS; Kratos Analytical).

The magnetic properties were evaluated using a Quantum Design Dynacool physical property measurement system (PPMS) equipped with a vibrating sample magnetometer (VSM ). Magnetic hysteresis loops were measured at temperatures between 10 and $300 \mathrm{~K}$ and the magnetization at 10000 Oe was measured for a temperature interval of $10-400 \mathrm{~K}$.

\section{Conclusions}

We have developed a new promising ALD process based on the zero-valent manganese precursor complex $\mathrm{Mn}_{2}(\mathrm{CO})_{10}$ for the controlled fabrication of crystalline manganese oxide thin films. Ozone is employed as the oxygen source in the process. The process yields homogeneous thin films with an appreciably high growth rate of ca. $1.2 \AA$ per ALD cycle in the low deposition temperature range of $80-160{ }^{\circ} \mathrm{C}$. The low deposition temperature saves energy and allows the use of temperaturesensitive substrates. Most importantly, it enables the growth of manganese oxide thin films with the $\alpha-\mathrm{Mn}_{2} \mathrm{O}_{3}$ structure in the lowest temperature region from 80 to $100{ }^{\circ} \mathrm{C}$. This is a novel advantage of our $\mathrm{Mn}_{2}(\mathrm{CO})_{10}+\mathrm{O}_{3}$ process as there are no ALD processes previously reported for $\mathrm{Mn}_{2} \mathrm{O}_{3}$ thin films. Upon increasing the deposition temperature to or above $120{ }^{\circ} \mathrm{C}$, spinel-structured ferrimagnetic $\mathrm{Mn}_{3} \mathrm{O}_{4}$ thin films are obtained. The two manganese oxide materials both have interesting future application possibilities which would require/benefit from e.g. thin-film depositions on sensitive/flexible/nanostructured substrates. We foresee that our new lowtemperature ALD process enabling the controllable deposition of $\mathrm{Mn}_{2} \mathrm{O}_{3}$ and $\mathrm{Mn}_{3} \mathrm{O}_{4}$ thin films by adjusting the deposition temperature could be of considerable interest for such applications.

\section{Acknowledgements}

The work has received funding from the European Research Council under the European Union's Seventh Framework Programme (FP/2007-2013)/ERC Advanced Grant Agreement (NO. 339478). Dr. Leena-Sisko Johansson is acknowledged for carrying out the XPS measurements. 


\section{Notes and references}

1 F. Cheng and J. Chen, Chem. Soc. Rev., 2012, 41, 2172-2192.

2 W. Wei, X. Cui, W. Chen and D. G. Ivey, Chem. Soc. Rev., 2011, 40, 1697-1721.

3 M. J. Young, M. Neuber, A. C. Cavanagh, H. Sun, C. B. M usgrave and S. M. George, J. Electrochem. Soc., 2015, 162, A2753-A2761.

4 S. Isber, E. Majdalani, M. Tabbal, T. Christidis, K. Zahraman and B. Nsouli, Thin Solid Films, 2009, 517, 1592-1595.

5 A. R. Merritt, R. Rajagopalan and J. D. Carter, Thin Solid Films, 2014, 556, 28-34.

6 O. Nilsen, H. Fjellvåg and A. Kjekshus, Thin Solid Films, 2003, 444, 44-51.

7 O. Nilsen, S. Foss, H. Fjellvåg and A. Kjekshus, Thin Solid Films, 2004, 468, 65-74.

8 O. Nilsen, S. Foss, A. Kjekshus and H. Fjellvåg, J. Nanosci. Nanotechnol., 2008, 8, 1003-1011.

9 B. B. Burton, F. H. Fabreguette and S. M. George, Thin Solid Films, 2009, 517, 5658-5665.

10 S. M. George, Chem. Rev., 2010, 110, 111-131.

11 V. Miikkulainen, M. Leskelä, M. Ritala and R. L. Puurunen, J. Appl. Phys., 2013, 113, 021301.

12 V. M iikkulainen, A. Ruud, E. Ostreng, O. Nilsen, M. Laitinen, T. Sajavaara and H. Fjellvåg, J. Phys. Chem. C, 2014, 118, 87228722.

13 K. L. Pickrahn, S. W. Park, Y. Gorlin, H. Lee, T. F. Jaramillo and S. F. Bent, Adv. Energy M ater., 2012, 2, 1269-1277.

14 K. Uusi-Esko, J. M alm and M. Karppinen, Chem. Mater., 2009, 21, 5691-5694.

15 K. Uusi-Esko, E.-L. Rautama, M. Laitinen, T. Sajavaara and M Karppinen, Chem. Mater., 2010, 22, 6297-6300.

16 K. Uusi-Esko and M. Karppinen, Chem. Mater., 2011, 23, 18351840.

17 Y. W. Li, Q. Qiao, J. Z. Zhang, Z G. Hu and J. H. Chu, Thin Solid Films, 2015, 574, 115-119.

18 F. Mattelaer, P. M. Vereecken, J. Dendooven and C. Detavernier, Chem. Mater., 2015, 27, 3628-3635.

19 K. L. Pickrahn, A. Garg and S. F. Bent, ACSCatal., 2015, 5, 16091616.

20 K. L. Pickrahn, Y. Gorlin, L. C. Seitz, A. Garg, D. Nordlund, T. F. Jaramillo and S. F. Bent, Phys. Chem. Chem. Phys., 2015, 17, 14003-14011.

21 X. Qin, H. Sun and F. Zaera, J. Vac. Sci. Technol. A, 2012, 30, $01 \mathrm{~A} 112$.

22 X. Qin and F. Zaera, ECS J. Solid State Sci. Technol., 2014, 3, Q89-Q94.

23 N. C. Strandwitz, D. J. Comstock, R. L. Grimm, A. C. NicholsNielander, J. Elam and N. S. Lewis, J. Phys. Chem. C, 2013, 117, 4931-4936.

24 M. C. Biesinger, B. P. Payne, A. P. Grosvenor, L. W. M. Lau, A. R. Gerson and R. St. C. Smart, Appl. Surf. Sci., 2011, 257, 2717 2730.

25 V. Di Castro and G. Polzonetti, J. Electron Spectrosc. Rel. Phenom., 1989, 48, 117-123.

26 J. M alm, E. Sahramo, J. Perälä, T. Sajavaara and M . Karppinen, Thin Solid Films, 2011, 519, 5319-5322.

27 K. Dwight and N. Menyuk, Phys. Rev., 1960, 119, 1470-1479.

28 B. Boucher, R. Buhl and M. Perrin, J. Appl. Phys., 1971, 42, 1615-1617.

29 I. K. Gopalakrishnan, N. Bagkar, R. Ganguly and S. K. Kulshreshtha, J. Cryst. Growth, 2005, 280, 436-441

30 D. G. Wickham and W. J. Croft, J. Phys. Chem. Solids, 1958, 7 351-360.

31 I. S. Jacobs, Evidence for Triangular Moment Arrangements in M O-M n2O3, 1959, 30, S301.

\section{Graphical abstract}

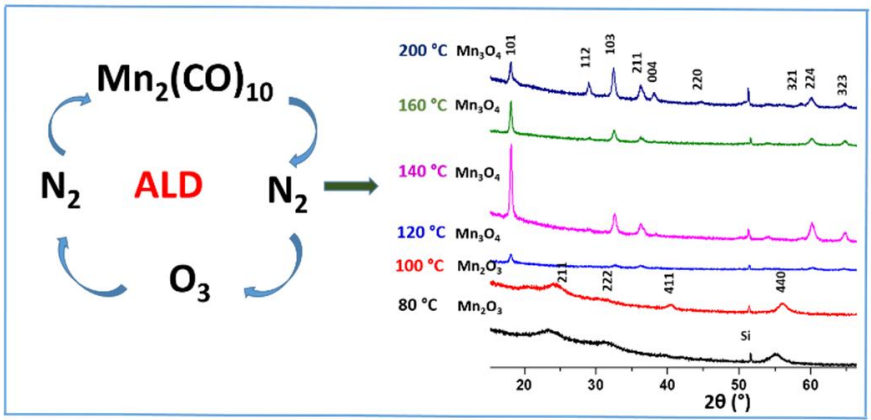

